\title{
Comparative Physico Mechanical Study of Cements CEM II 42.5R in Cameroon: Case of DANGOTE and CIMENCAM
}

\author{
Thomas d'Aquin Biyindi' ${ }^{1}$, Fabrice Kwefeu Mbakop ${ }^{1,2 *}$, Eric Toumi ${ }^{1,3}$, \\ Belmondo Woumbeng Etonleu', Joseph Pondi1,3
}

\begin{abstract}
${ }^{1}$ Department of Civil Engineering, Higher School of Sciences and Polytechnic Studies and Ethics, Yaoundé, Cameroon ${ }^{2}$ Department of Renewable Energy, National Advanced Polytechnic School, University of Maroua, Maroua, Cameroon ${ }^{3}$ Department of Mechanical Engineering, National Advanced Polytechnic School, University of Yaounde I, Yaounde, Cameroon Email: *mbakop.fabrice@yahoo.fr
\end{abstract}

How to cite this paper: Biyindi, T.A., Mbakop, F.K., Toumi, E., Etonleu, B.W. and Pondi, J. (2019) Comparative Physico Mechanical Study of Cements CEM II 42.5R in Cameroon: Case of DANGOTE and CIMENCAM. Open Journal of Civil Engineering, 9, 18-34.

https://doi.org/10.4236/ojce.2019.91002

Received: October 18, 2018

Accepted: February 22, 2019

Published: February 25, 2019

Copyright $\odot 2019$ by author(s) and Scientific Research Publishing Inc. This work is licensed under the Creative Commons Attribution International License (CC BY 4.0).

http://creativecommons.org/licenses/by/4.0/

\begin{abstract}
The present work deals with a comparative study of the physical-mechanical characteristics of different types of cement CEM II 42.5R produced and used in Cameroon. Indeed, the recent policy of integration and promotion of products in the sub-region has allowed some manufacturers (04) to settle in Cameroon and propose their products that characteristics are most often ignored by consumers. In order to handle this work correctly, we have conducted several tests on cements CEM II 42.5R of CIMENCAM and DANGOTE. These trials were carried out on fresh concrete, mortar, and also on a normalized cement paste. The present study mainly shows the specificities and the characteristics of CEM II 42.5R cement from other brands.
\end{abstract}

\section{Keywords}

Cement, Compression, CEM II 42.5R, Concrete, Mortar

\section{Introduction}

Cements are hydraulic binders made of fine powders which, if they are added to water, they form a paste that is able to hydrate and gradually harden after a longer or shorter time [1]. They are in fact composed of anhydrous, crystalline or vitreous constituents, essentially containing silica, alumina and lime. Moreover, the hardening is due to the hydration of certain components, mainly silicates and calcium aluminates; the proportion of lime and reactive silica to be at least $50 \%$ of the cement mass [1] [2] [3] [4]. 
Cement has been used for millennia: in ancient Egypt, it was a plaster mortar that bounded the stones. Chinese or the Mayas also use to build using limebased mortars, obtained by baking limestone rocks: this is the basis of the cement still manufactured today. Over the centuries, cement has been perfected. The Romans used lime which is reinforced by volcanic ash (pozzolana) to make their mortar this was then able to take under water. The empirical methods were perfected later on with the theory of hydraulicity and described the necessary proportions of lime and clay to produce cement by baking. From this, the industrial production of cement can start [4] [5] [6]. In 1824, Joseph Aspdin, a Scottish, improved the "recipe" and created Portland Cement. But it is in France that the Polytechnic Pavin de Lafarge settled his first lime kilns at Teil, in Ardèche, in 1833 [4].

The cement industry now is available to the user with large numbers of brands and specific areas of employment. The wide range of compositions, strengths, setting velocity and hardening combine with the requirements for the construction of buildings or civil engineering structures [6] [7] [8]. However in Cameroon, the cement plant has grown exponentially. So in addition to CIMENCAM, we have seen the establishment of DANGOTE, MEDCEM, and CIMAF. Each cement plant has a specificity in the mineralogical and chemical composition of the cements manufactured according to the geological context, the atmospheric conditions and the need for performance [4].

Cameroon cement plants produce, several types of cements including CEM II 42.5 R. So the composition varies from one cement plant to another. There are advantages solicited following the significant demand of the builders for the realization of works of civil engineering and real estate. The success of a structure depends on the mastery of the characteristics of the cement, the inputs (aggregates and water) and the atmospheric conditions [1]-[9]. However, it has been found that manufacturers sometimes neglect these parameters during the construction of structures, particularly the characteristics of cements [7]-[13]. Figure 1 shows the cement manufacturing process.

The purpose of this study is to present the specificities of CEM II $42.5 \mathrm{R}$ cement from each cement plant (Case of CIMENCAM and DANGOTE) and the areas of use that arise from these properties. The first part will be devoted to the generality of the cements, as well as to the materials and methods used. And the second part will be dedicated to the experimental study, namely a comparative study of CEM II $42.5 \mathrm{R}$ cement produced by CIMENCAM and DANGOTE, followed by an analysis of the results and by the recommendations.

\section{Materials and Methods}

This part is devoted to materials and methods. We will begin by presenting the characterization of materials that will be summarized in the presentation of the general properties and the mechanical and physical characteristics of the materials used. Finally we will present the experimental devices that allowed us to test 
the aggregates, cements and concrete (fresh and hardened).

\subsection{The General Properties of Aggregates}

\subsubsection{Particle size Analysis after Sieving.}

Granulometric analysis makes it possible to characterize the aggregates by determining the size of the grains which constitute them, and the percentages of the grains of each size. It is carried out with sieves (Figure 2) according to standard NF P 18-560 [14]. In addition, it will be necessary to avoid confusing grain size, which is the science that determines grain size and granularity, which is a dimensional distribution of grains of a granulate [5].

The studied material is placed at the top of the sieves and the classification of the grains is obtained by vibration of the sieve column. At the end of the test, we draw the particle size curve which gives the respective weight percentages of

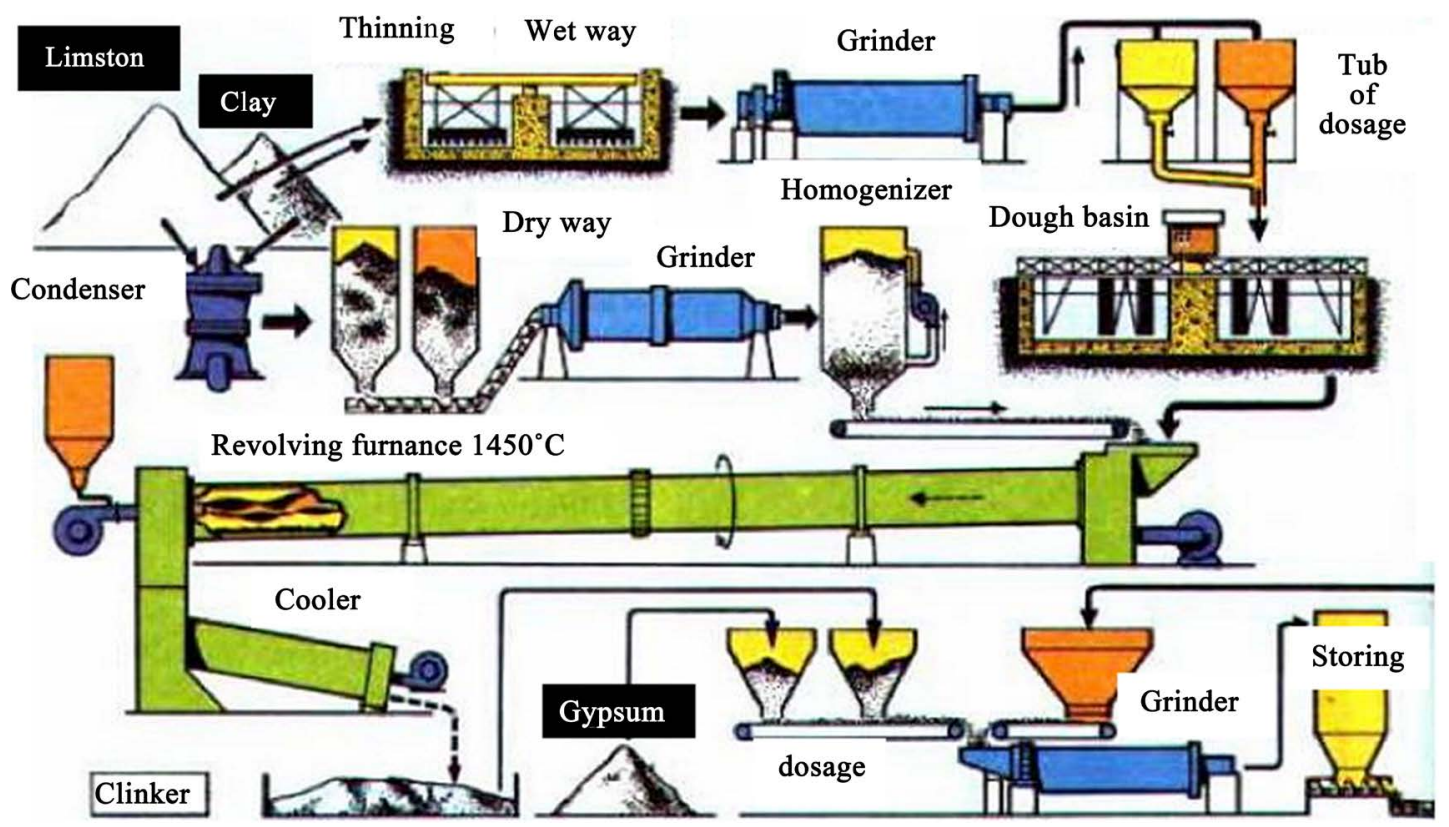

Figure 1. The cement manufacturing process [9].

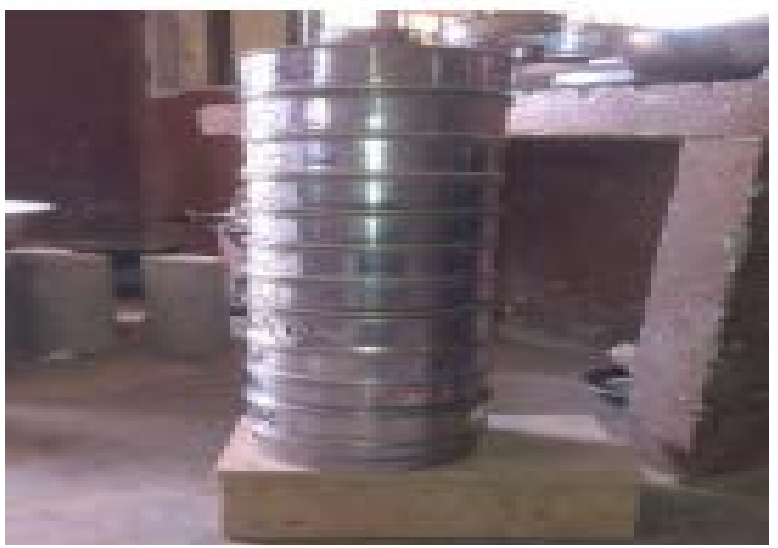

Figure 2. Series of sieves used for sieve size analysis. 
different families of grains constituting the material. From the granulometric curve, certain indicators are determined for characterizing the material. These include the coefficients of uniformity $(\mathrm{Cu})$ and curvature $(\mathrm{Cc})$ defined respectively by Equations (2) and (3). Finally, the fineness module ( $M d f$ ) for sand [15]-[20] is calculated.

$$
\begin{gathered}
C u=\frac{D_{60}}{D_{10}} \\
C c=\frac{\left(D_{30}\right)^{2}}{D_{10} \cdot D_{60}}
\end{gathered}
$$

$D_{10}, D_{30}, D_{60}$ represent the diameters of the elements corresponding to $10 \%$, $30 \%$ and $60 \%$ of cumulative sieve, respectively. When we have:

$\mathrm{Cu}<2$, the particle size is said to be uniform

$\mathrm{Cu}>2$, the particle size is said to be spread

A sand is well graduated when one has: $1 \leq C c \leq 3$ [27]

$M d f=\frac{1}{100} \sum$ Cumulative refusal in $\%$ of $d(\mathrm{~mm})$ sieves $\{0,16 ; 0,315 ; 0,63 ; 1,25 ; 2,5 ; 5\}$

\subsubsection{Sand Equivalent to $10 \%$ Fines}

The equivalent of sand is used to measure the cleanliness of the sand and to detect the presence of fine elements in this sand. It is carried out according to the standard NFP 18 - 598 [15]-[21]. It is the ratio multiplied by 100 of the height of the sedimented sandy part, at the total height of the flocculate and the sandy part [15]. The test is to flocculate the fine elements of sand suspended in a washing solution and then, after a time of rest, to measure the height of the sedimented elements.

$$
E S=100 \times \frac{h_{2}}{h_{1}}
$$

With:

- $h_{1}$ : clean sand height + fine elements,

- $h_{2}$ : clean sand height only.

Figure 3 shows the device used to perform the aforementioned test.

\subsection{Mechanical and Physical Properties of Aggregates}

\subsubsection{Resistance to Fragmentation}

In order to verify the resistance to fragmentation, the Los Angeles test was carried out according to the NF EN 1097-2 standard and is intended to measure the resistance to shock fragmentation of a sample of aggregates. Indeed, it is expressed by the coefficient Los Angeles $\left(L_{A}\right)$ which is the ratio between the mass of the refusal to sieve $1.6 \mathrm{~mm}$ of the sample after passage in the apparatus (Figure 4) intended for the test on mass initial [7] [18]. The coefficient $L_{A}$ is determined as follows: 


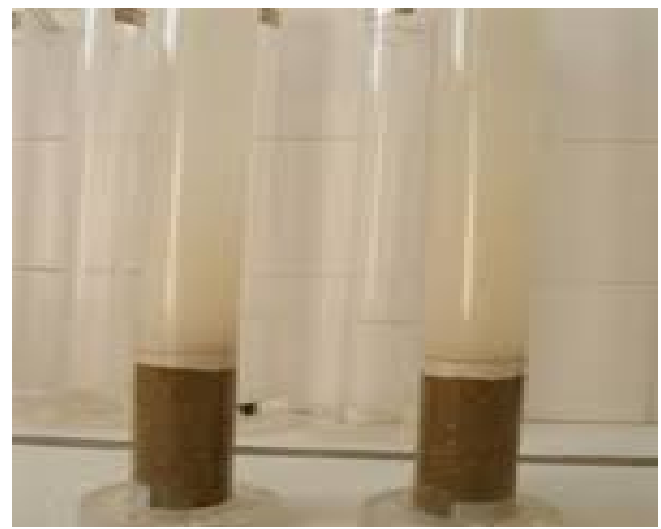

Figure 3. Sand equivalent test.
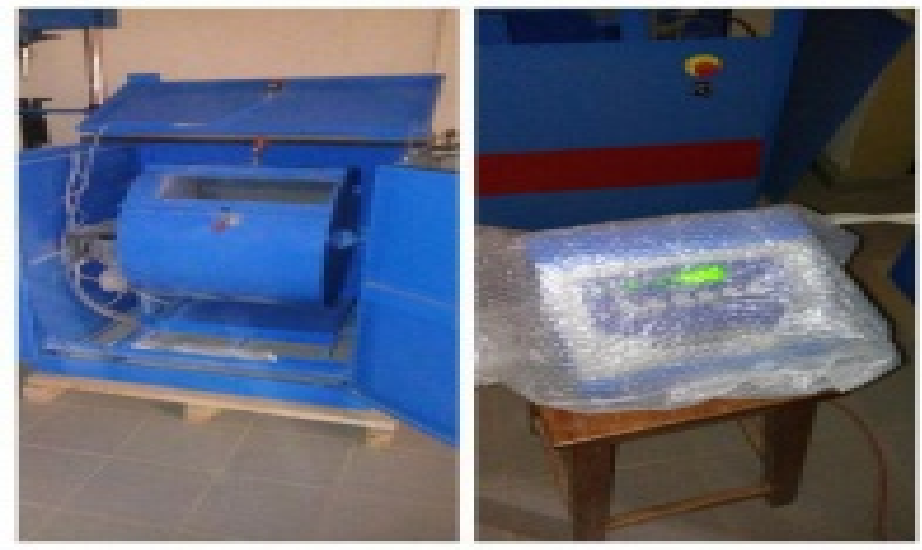

Figure 4. Apparatus for los angeles trial.

$$
L_{A}=\frac{P}{M} \times 100 \text { avec } p=M-m
$$

With. $P$. mass of sieve passing $1.6 \mathrm{~mm}(\mathrm{~g})$,

$M$ : mass of materials collected (g),

$m$ : mass of dry refusal (g).

\subsubsection{Wear Resistance: Micro-Deval Test}

The purpose of the micro-Deval test is to verify under standard conditions the input of the aggregates produced by mutual friction in the presence of water and an abrasive load in a rotating cylinder. This test is carried out according to standard NF EN 1097-1. Indeed, after abrasion and depoits in a rotating cylinder arranged on a device as shown in photo 4 (12,000 revolutions in 2 hours), the mass $\mathrm{m}$ of the elements less than $1.6 \mathrm{~mm}$ produced, in the presence of water and expressed by the micro-Deval coefficient $\left(M_{D E}\right)$ [7] [19]-[24]. The $M_{D E}$ coefficient is determined as follows:

$$
M_{D E}=\frac{P}{M} \times 100 \text { avec } P=M-m
$$

With $P$ : passing mass of sieve $1.6 \mathrm{~mm}(\mathrm{~g})$, 
M: mass of materials collected (g),

$m$ : mass of dry refusal (g).

\subsubsection{Specific Density}

The specific density is the mass of the unit of absolute volume of the body, that is to say, the material that constitutes the body, without taking into account the volume of the voids [2]. It varies from 2900 to $3150 \mathrm{~kg} / \mathrm{m}^{3}$ depending on the type of cement [10]. It is measured in two ways: using the graduated cylinder or using the pycnometer. Indeed, the test specimen method is very simple, fast and uses standard laboratory equipment (graduated test tube) except that it is of low precision [7]. In addition, the pycnometer test is carried out according to the EN 1097-6 standard. The density of the aggregates (sand and gravel) used was measured using the graduated cylinder (Figure 5(a)) and the cement using the glass pycnometer (Figure 5(b)) [7] [20]-[27].

\subsection{Mechanical and Physical Properties of Cements}

\subsubsection{Measurement of Finesse}

The fineness of cement is generally expressed by its mass area. This is the total area of the grains contained in a unit of powder. The objective of the test is to assess the surface area of the cement grains per gram of powder [7]. This surface is expressed in $\mathrm{cm}^{2} / \mathrm{g}$. The test for the determination of the fineness of the cement is carried out according to the EN 196-1 standard. The mass surface of the cements studied is measured by comparison with a reference cement that surface area is known [8] [14]-[25]. The equipment used to carry out the test is called the "Blaine Permeabilimeter".

Indeed it will be to pass a known volume of air through cement powder. The larger is the surface of this powder, the longer it takes for the air to pass through the powder.

\subsubsection{Consistency Measurement}

The consistency test of the dough makes it possible to characterize its greater or lesser fluidity. The following standardized tests make it possible to appreciate
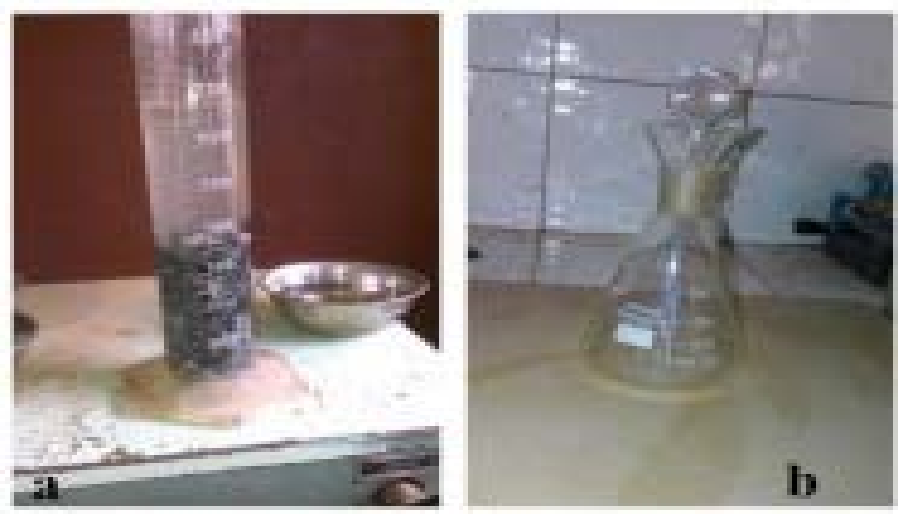

Figure 5. Graduated cylinder and pycnometer for the measurement of specific gravity. 
this consistency:

- Consistency test carried out with the Vicat apparatus according to EN 196-3

- The cone flow test according to standard NF P 15-358 [25].

As part of our work, we evaluated this consistency from the Vicat consistency. Indeed it consists in measuring the depression of a cylindrical rod under the effect of a constant load in the dough. Indeed, it is the distance " $d$ " between the end of the probe and the bottom of the mold that characterizes the consistency. If " $\mathrm{d}=6 \mathrm{~mm} \pm 1 \mathrm{~mm}$ " the consistency is called "normalized" [7] [8]. The equipment used is shown in Figure 6.

\subsubsection{Measurement of Setting Time}

The test is carried out on a paste of standardized consistency and is made according to the EN 196-3 standard. The objective of the test is to define for given cement a time that is significant for the speed of setting. It is the evolution of the consistency of a paste of standardized consistency that will be followed by the test. The apparatus used is that of Vicat equipped with a $1.13 \mathrm{~mm}$ diameter needle as shown in Figure 7. It is said that the "setting start time" is reached when under the effect of a load of $300 \mathrm{~g}$, the needle stops at a distance " $\mathrm{d}=4 \mathrm{~mm}$ $\pm 1 \mathrm{~mm}$ " from the bottom of the mold. In addition, the "end of setting time" is the one at the end of which the needle is no more than $0.5 \mathrm{~mm}$ [7] [8].

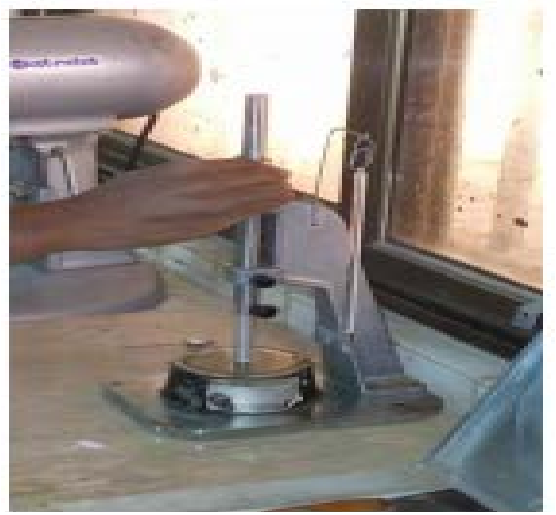

Figure 6. Vicat device with $10 \mathrm{~mm}$ diameter probe.

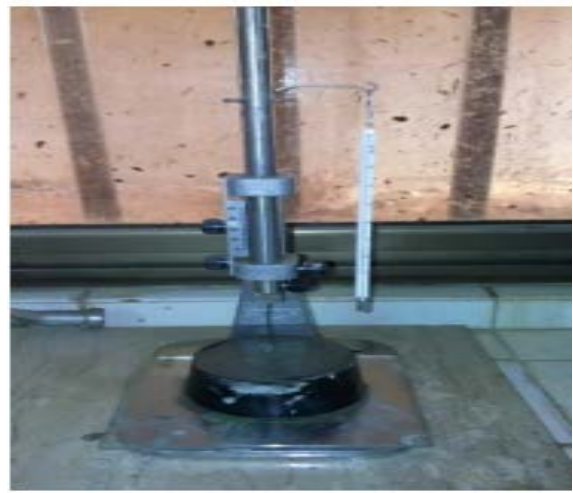

Figure 7. Vicat apparatus equipped with a $1.13 \mathrm{~mm}$ needle for the setting test. 


\subsection{Properties of Fresh Concretes}

\subsubsection{Slump cone of Abrams or Slump Test}

Abrams cone collapse is carried out according to standard NF EN 12350-2 and is very often used because it is quite easy to implement [7] [8] [23]. It consists of molding in a truncated cone whose diameter of the base is $20 \mathrm{~cm}$, the top is 10 $\mathrm{cm}$ and height $30 \mathrm{~cm}$ of the concrete. The cone is filled in three layers each poked 25 times with a metal rod $16 \mathrm{~mm}$ in diameter with rounded ends. Then gently lift the mold and measure the slump immediately after.

The mold is then gently raised and the slump or slump measured immediately afterwards (Figure 8(a)).

\subsubsection{Making Concrete Specimens}

The concrete is first kneaded in a concrete mixer or kneader, and then molded in molds $16 \mathrm{~cm}$ in diameter and $32 \mathrm{~cm}$ in height (Figure 9(a)). Finally the molds are put on a vibrating table for tightening the concrete. Moreover, the tightening time depends on the consistency of the concrete. The standard NF EN 12390-1 is the one that regulates the dimensions of molds. The test pieces must remain in the mold and be protected against shocks, vibrations and desiccation for at least 16 hours and up to 3 days at a temperature of $25^{\circ} \mathrm{C} \pm 5^{\circ} \mathrm{C}$ in hot countries and $20^{\circ} \mathrm{C} \pm 5^{\circ} \mathrm{C}$ [22]. After demolding, the concretes are kept in a maturation basin (Figure 9(b)) until the expected day of crushing [22] [23] [24] [25].
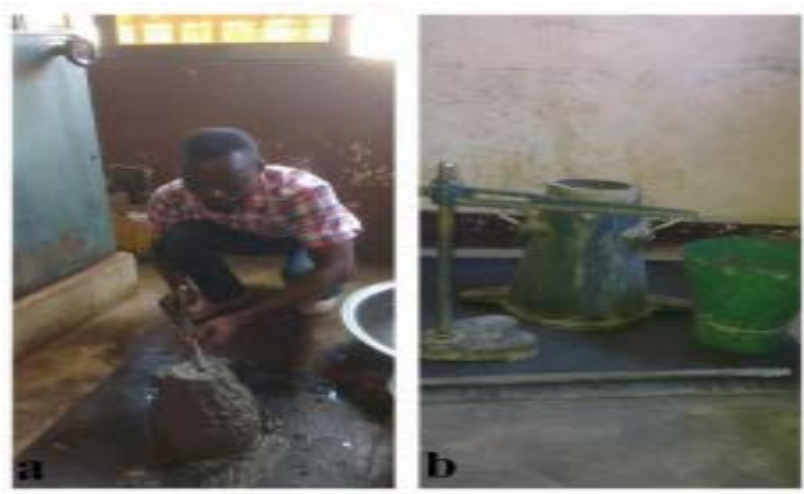

Figure 8. Measurement of subsidence and cone of Abrams and its accessories.
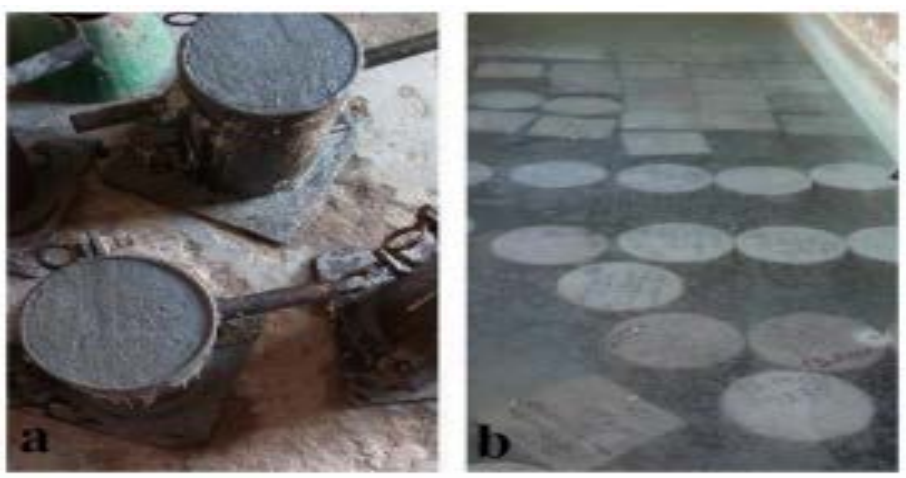

Figure $9.16 \mathrm{~cm} \times 32 \mathrm{~cm}$ mold and concrete curing tray. 


\subsubsection{Evolution of the Semi-Wet Density of Concrete}

Density, also called density mass density, is a physical quantity that characterizes the mass of a material per unit volume. It is determined according to the raio:

$$
\rho=\frac{m}{V}
$$

With $m$ which is the mass of the homogeneous substance occupying volume V.

\section{Flowchart of the Stages of the Experiment}

This experimental work is clearly presented in stages on the flowchart of Figure 10.

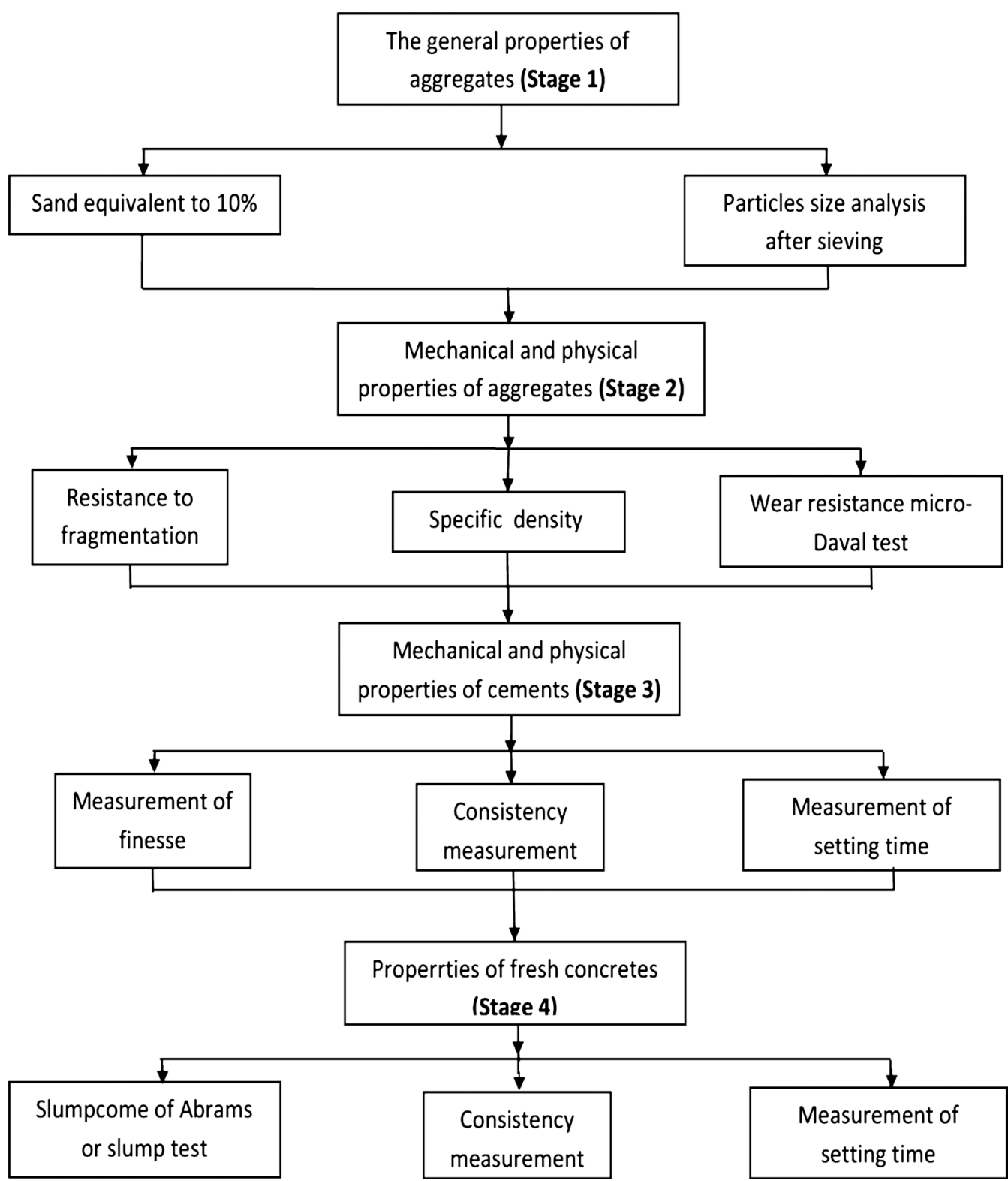

Figure 10. Flow chart of the experiment steps. 


\section{Results and Discussion}

\subsection{Measurement of Finesse}

The fineness of a cement is generally expressed by its mass area. Table 1 presents the results obtained following the fineness test on the two different cements studied.

Figure 11 shows the results obtained following the fineness test on the two different studied cements

The finer the value of a cement, the finer the grinding. We can see that CIMENCAM has a greater grinding fineness. Note that the finer the milling of a cement, the higher the speed of hydration reactions and the higher the mechanical resistance at young ages ( 2 to 7 days). On the other hand, cement is sensitive to ventilation and large shrinkage [7].

\subsection{Consistency Tests}

Table 2 shows the consistency in $\%$ of the various cements studied.

Table 1. Blaine fineness of the cements studied.

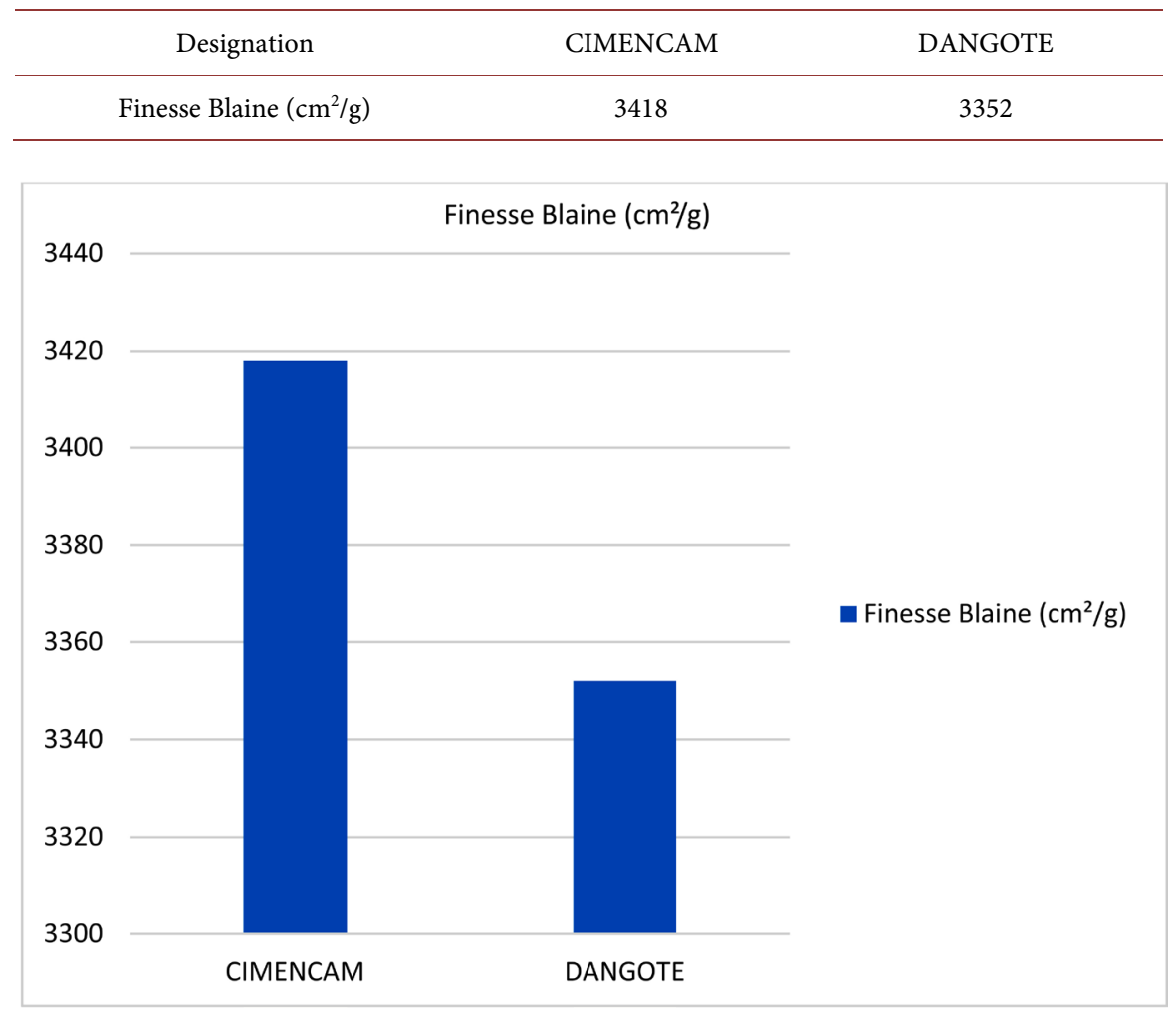

Figure 11. Graph showing the fineness of Blaine of the cements studied.

Table 2. Consistencies of the cements studied.

\begin{tabular}{ccc}
\hline Designation & CIMENCAM & DANGOTE \\
\hline Consistency (\%) & 32 & 30 \\
\hline
\end{tabular}


Figure 12 presents the results obtained following the consistency test on the two different cements studied.

From the results obtained, we find that CIMENCAM needs a large quantity of water to reach the consistency required by the EN 196-3 standard.

\subsection{Setting Time}

We talk about the setting of cement when the paste of cement, mortar or concrete loses its plasticity. In the course of our work, we have determined these different times on the various cements used (see Figure 13).

It was on the standardized cement paste made during the consistency test that

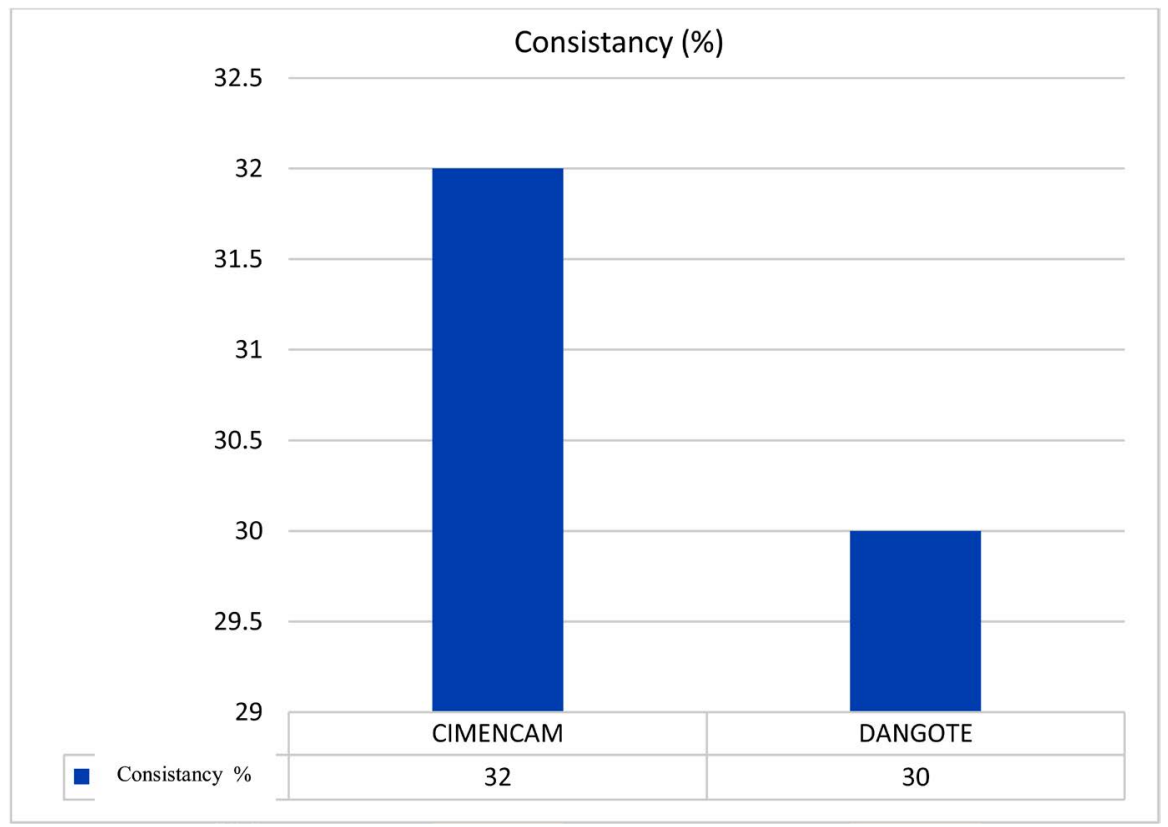

Figure 12. Graph showing the consistency of the cements studied.

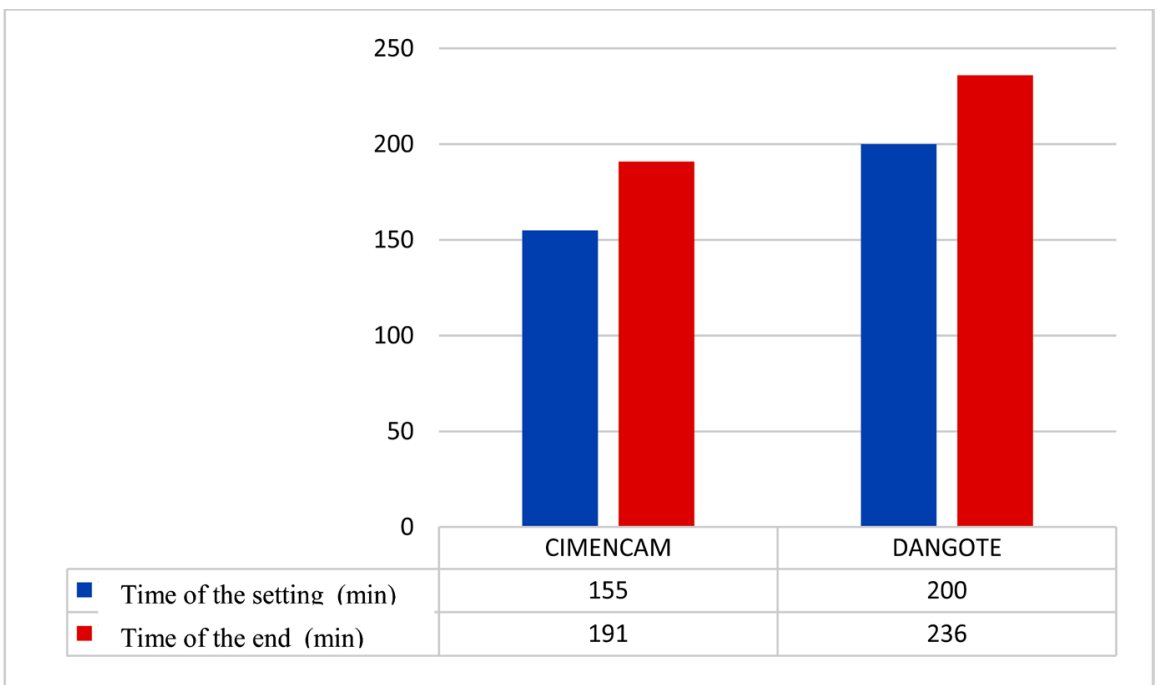

Figure 13. Graph showing the setting time of the studied cements. 
we carried out the setting time test. As it can be seen in Figure 13, setting times vary from one cement to another. They are well above 75 minutes as provided by EN 197-1 for CEM II 42.5N and CEMII 42.5R cements. The setting time can be influenced by several factors such as the fineness of the cement, its chemical composition, the ambient temperature and the effect of the adjuvant if there are any. Thus, the setting time is faster for cement when it has great fineness [7] [8] [18]-[27]. In view of the results obtained, we can see that CIMENCAM has a setting start time lower than that of DANGOTE is ground more finely. In addition, the results we obtained are consistent with those of Blaine finesse. Indeed, the finer a cement is, the greater its specific surface is, the shorter is its setting time and the faster it flows. However, since DANGOTE has a more advanced setting time than CIMENCAM, it also has the advantage of less cracking and less shrinkage [1].

\subsection{Abrams Cone Settlement of Fresh Concrete}

The histogram presented in Figure 14 shows the value of the slump measured on concretes made from the various cements studied.

The slump allows us to see the workability of the various concretes made. So we can notice that CIMENCAM cement is more open than DANGOTE cement. The loss of height is due to the fluidity of each type of cement, the large aggregates $(25 \mathrm{~mm})$ contained in the gravel and the amount of water introduced during the making of concrete. Indeed, water is a very important parameter in the workability of a concrete. For the preparation of the various concretes, we have introduced the same quantity of water and obtained different values of subsidence but we can note that these concretes are very plastics on the one hand (10

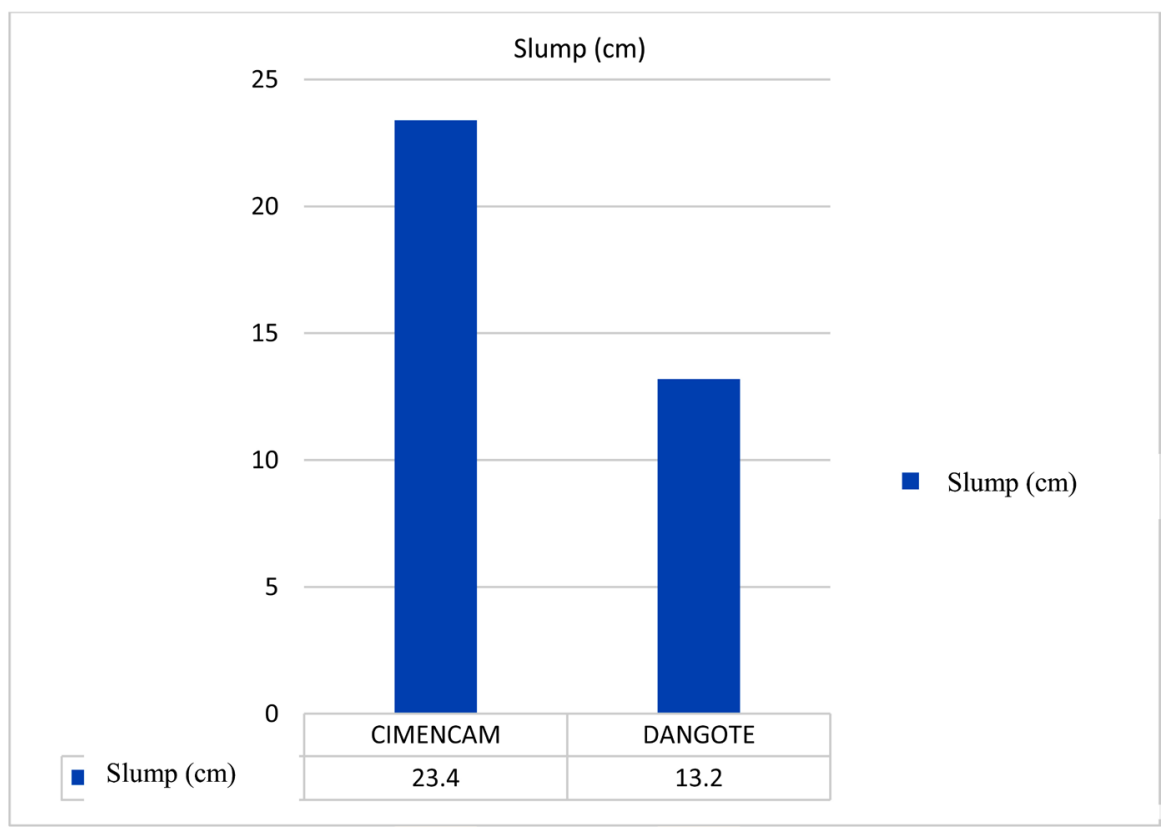

Figure 14. Graph showing the slump of fresh concrete of the studied cements. 
$<$ SLUMP $<15)$ and fluid of other part $(16<$ SLUMP $<21)$.

\subsection{Density of Fresh Concrete}

The fresh density is measured in order to be able to verify the density calculated theoretically. The fresh densities of the different types of cement studied are shown in Figure 15.

The density theoretically calculated following the formulation that we made, allowed us to obtain $2.99 \mathrm{t} / \mathrm{m}^{3}$. Thus we can see that the fresh concrete densities obtained are different and below the theoretical. The characteristics of the studied cements and the mechanism of hydration can explain this difference. It should also be noted that the phenomenon of contraction of materials may have an influence on this difference. Indeed, this measure should make it possible to make corrections on the proportions of the constituents of the concrete.

\subsection{Semi-Wet Density}

Mass volume is defined as the mass of a body per unit volume. During the cooking period, we measured the density of the test specimens at different ages, as shown in Figure 16.

During our study, we observed that the concretes studied have densities ranging from $2 \mathrm{t} / \mathrm{m}^{3}$ to $2.5 \mathrm{t} / \mathrm{m}^{3}$. Indeed, the more the maturation evolves, the more the density increases. This is due to the fact that immersed in the maturation pond, concretes become saturated as and when they mature.

\subsection{Compressive Strength}

The compressive strength on the concrete specimens makes it possible to determine

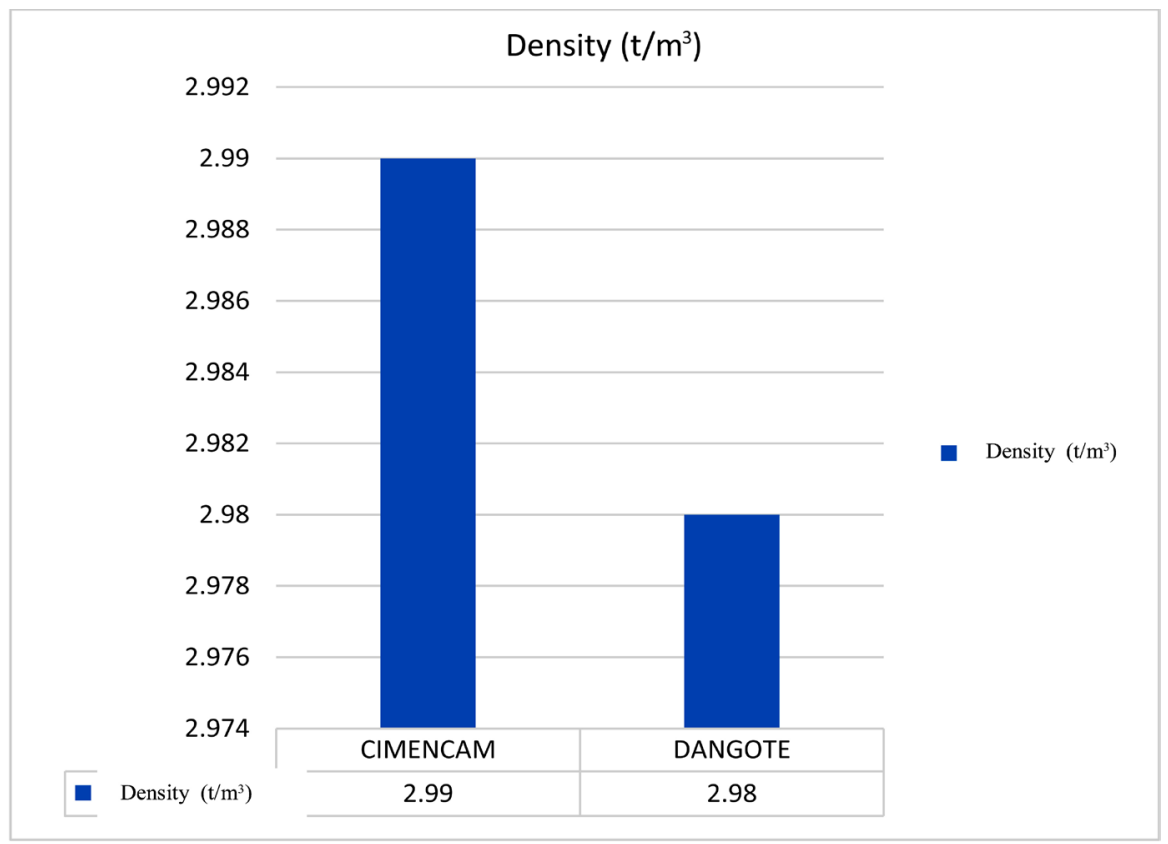

Figure 15. Graph presenting the density values of fresh concrete of the studied cements. 


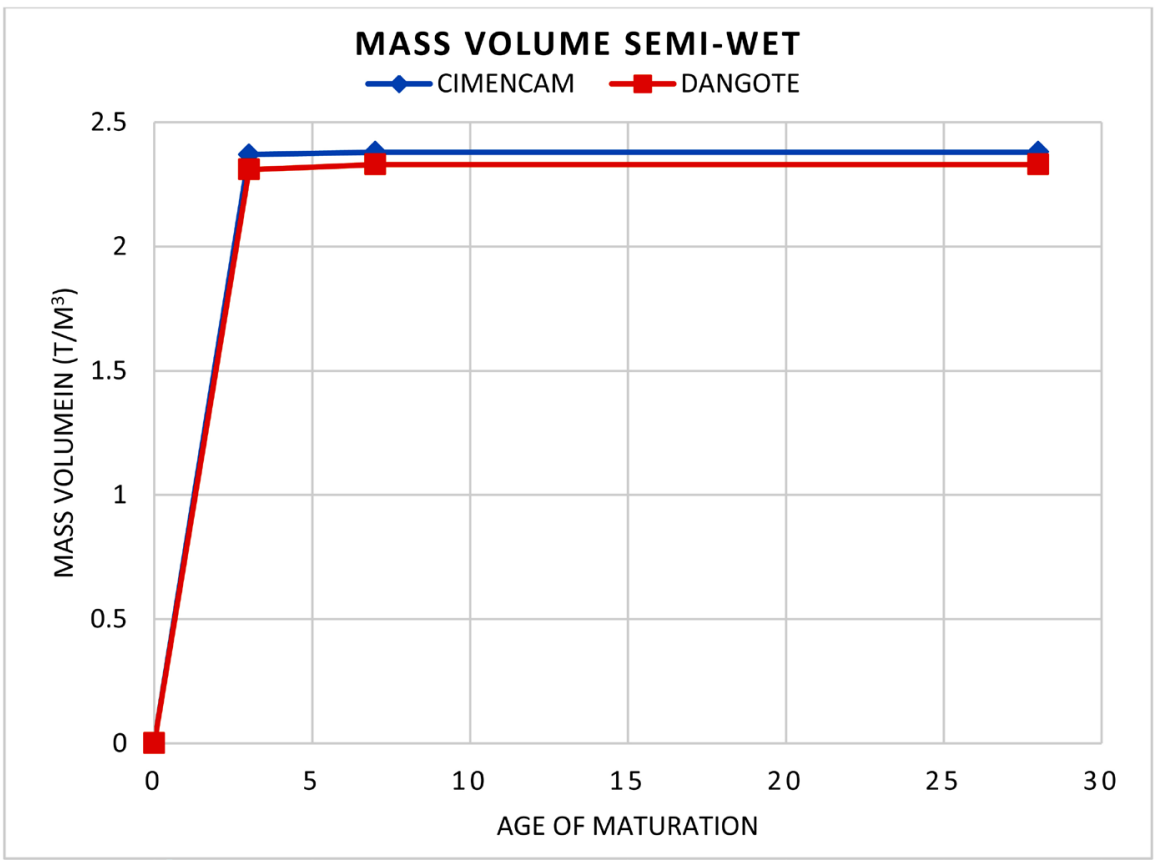

Figure 16. Semi-wet density of hardened concrete as a function of aging age.

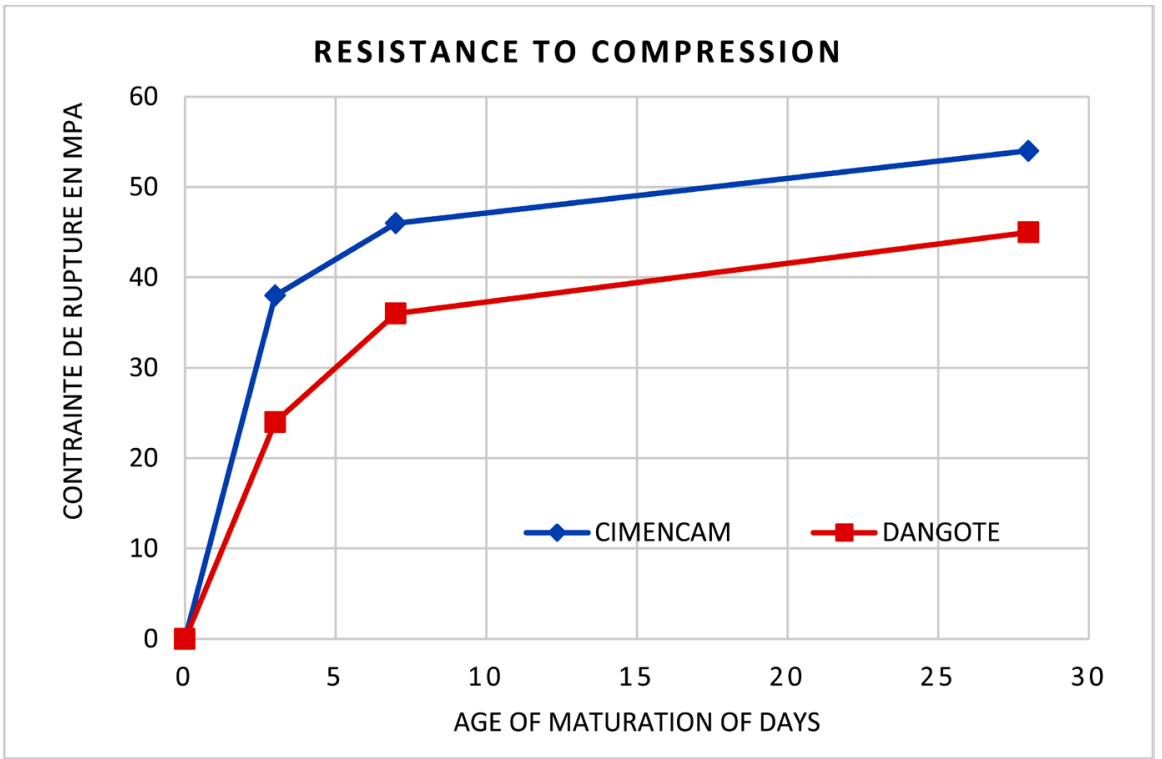

Figure 17. Resistance to compression at different days of maturation.

the characteristic value of the concrete strength. Indeed it is the most sought after feature on hardened concrete. As part of our work, we determined the compressive strengths of concrete specimens at 3 days, 7 days and 28 days (see Figure 16).

We can see in Figure 17, a growth of the compressive strength during the maturation of the concrete. This evolution is due to several factors among others: the hydrates released during the hydration, the quality of the granular skeleton (mechanical quality of the aggregates, capacity of adhesion of the mixture 
sand and gravel with the cement paste) of the concrete and the class resistance of cement [7]. Note that between the $3^{\text {rd }}$ day and $7^{\text {th }}$ day, we notice that the resistance has hardly changed and then from the $14^{\text {th }}$ day begins again to grow until $28^{\text {th }}$ days. Indeed, it is $35.3 \mathrm{MPa}$ (increase of $32 \mathrm{MPa}$ of $15 \%$ taking into account the environment and the quality of the aggregates used to make the concrete) that we hoped to have at least at the outcome of our calculations.

\section{Recommendations}

At the end of this analysis, it was discussed to make a comparative study between the characteristics of DANGOTE and CIMENCAM CEM II 42.5R cements. We remember that both have good characteristics (meeting the standards). Nevertheless, each of them presents a specificity in the face of a specific task:

- CIMENCAM has a fine particle size and a good resistance in short and long run young and long term, so it is recommended to use this cement for work requiring high strength such as beams, poles.

- On the other hand, DANGOTE, has a slightly coarser grain size, it is less exposed to shrinkage and venting, so it is recommended to use it for finishing work such as wall and floor covering, prefabrications. Filling element (cinder block, Urdis), the realization of the decorative elements.

\section{Conclusion}

Determining the physico-mechanical characteristics of the CEM II $42.5 \mathrm{R}$ cements used in Cameroon was the main objective of our study. For this purpose, we have carried out various tests on fresh and cured concrete, standard mortar and standard cementitious paste. Examples include cement setting tests, bending and compression tests on hardened concrete. The study was carried out from two cements encountered in Cameroon namely: CIMENCAM and DANGOTE. We stopped at 28 days which is the number of days at which the reference resistance to compression of concretes or mortars is determined. Hence the values of the 28-day compressive strengths on the mortar specimens are as follows: CIMENCAM (54 MPa) and DANGOTE (45 MPa). Thus we have been able to determine that CEM II $42.5 \mathrm{R}$ cements can be used in masonry for reinforced and stressed concrete that is to say for standard structures requiring high resistance. The results shown in our paper present in a non-exhaustive way, a general idea about the different types of CEM II $42.5 \mathrm{R}$ cements used in Cameroon.

\section{Conflicts of Interest}

The authors declare no conflicts of interest regarding the publication of this paper.

\section{References}

[1] Adam, M. (1982) Gide Practice for the Use of Cements. Eyrolles. 
[2] Festa, J. (1998) New Guide to Concrete and Its Constituents. Eyrolles.

[3] Dagou Houljakbe, A. (2015) Comparative Study of the Mechanical Characteristics of Cements used in Burkina Faso. Ouagadougou.

[4] Biyindi, A.T. (2007) Road Design Model in a Humid Tropical Environment: Case of the Eseka-Lolodorf Zone (South-Central Cameroon). 180 p.

[5] Lanchon, R. (1983) Laboratory Course, Granulates béton sol. Desforges.

[6] Mbakop, F.K., Djongyang, N., Ejuh, G.W., Woafo, P. and Raïdandi, D. (2017) Transmission of Light through an Optical Filter of a One-Dimensional Photonic Crystal: Application to the Solar Thermophotovoltaic System. Physica B, Elsevier, 92-99.

[7] Dupain, R. (1995) Aggregates, Soils, Cements, and Concretes. Casteilla.

[8] Touzouti, R. (2012) Introduction to Nanociments and Nanobetons.

[9] Dang, T.A. (2011) INSA of Rennes.

[10] Cimbeton (2005) Constituents of Concretes and Mortars. Fact Sheets, 1.

[11] Tchonda, T., Mawaba, E. and Ditouma, J. (2015) Concrete Formulation of Materials (Sand and Gravel) of the Bidjoounou River in the Prefecture of Tchaoudjo in Cameroon.

[12] Fabbris, F. (2013) The Rheology of Concrete. Fundamental Knowledge, Laboratory of Matter.

[13] Savadogo, N. (2013) Implementation of an Eco-Cement Based on Mineral Charcoal Machine.

[14] Excerpt from the May 2000 CD-ROM NOEMIE, NF P18-560: (1990) Sieve Analysis.

[15] Extract from the NOEMIE CD-ROM of May 2000, NF EN 1097-1_A1 (2004) Tests for Determine the Mechanical and Physical Characteristics of Aggregates. Microphone-Deval.

[16] Excerpt from the NOEMIE CD-ROM of May 2000, EN 196-1 (1995) Test Methods of Cements-Part 1: Determination of Mechanical Strengths. 15-471.

[17] Extract from the NOEMIE CD-ROM of May 2000, NF EN 206-1 (2004) Concrete, Part 1: Specification, Performance, Production and Compliance.

[18] From the May 2000 Issue of the NOEMIE CD-ROM, EN 196-3 (2009) Methods of Testing Cements-Part 3: Setting Time and Stability.

[19] Excerpt from the NOEMIE CD-ROM of May 2000, NF EN 1097-2 (1998) Tests for Determine the Mechanical and Physical Characteristics of Aggregates Resistance to Fragmentation.

[20] Extract from the NOEMIE CD-ROM of May 2000, NF EN 109-3 (1998) Determination of Mechanical and Physical Properties of Aggregates: Part 3: Method to Determine Bulk Density and Inter-Granular Porosity.

[21] Mbakop, K.F., Djongyang, N. and Raïdandi, D. (2016) One-Dimensional $\mathrm{TiO}_{2} / \mathrm{SiO}_{2}$ Photonic Crystal Filter for Thermophotovoltaic Applications. Journal of the European Optical Society-Rapid Publications, 12, 23.

[22] Extract from the NOEMIE CD-ROM of May 2000, NF EN 1097-6 (2006) Determination of Mechanical and Physical Properties of Aggregates: Part 3: Method to Determine the True Density and the Water Absorption Coefficient.

[23] Excerpt from the NOEMIE CD-ROM of May 2000, NF EN 12350-2: December (1999) Concrete Test Fees: Part 2: Slump Test.

[24] Extract from the NOEMIE CD-ROM of May 2000, NF EN 12390-3: December 
(2001) Concrete Test Hardened: Part 3: Compressive Strength of Test Pieces.

[25] Excerpt from the NOEMIE CD-ROM of May 2000, NF P18 357: July (1985) Admixtures for Concrete, Mortars and Grout. Injection Current Grout for Prestressing, Manufacture.

[26] Excerpt from the NOEMIE CD-ROM of May 2000, NF P18 358: July (1985) Admixtures for Concrete, Mortars and Grout. Injection Current Grouts for Prestressing, Measuring the Fluidity and Water Reduction.

[27] Extract from the NOEMIE CD-ROM of May 2000, NF EN 197-1 (2001) Cement. Part 1: Composition, Specifications and Conformity Criteria of Common Cement. 